\title{
Pilin expression and processing in pilus mutants of Neisseria gonorrhoeae: critical role of $\mathrm{Gly}_{-1}$ in assembly
}

\author{
M. Koomey, ${ }^{1,2, *}$ S. Bergstrom, ${ }^{3}$ M. Blake ${ }^{2}$ and \\ J. Swanson ${ }^{4}$ \\ ${ }^{1}$ Department of Microbiology and Immunology, The \\ University of Michigan Medical School, Ann Arbor, \\ Michigan 48109-0402, USA. \\ ${ }^{2}$ Laboratory of Bacteriology and Immunology, The \\ Rockefeller University, New York, 10021, USA. \\ ${ }^{3}$ Department of Microbiology, University of Umea, \\ S-90187, Umea, Sweden. \\ ${ }^{4}$ Department of Health and Human Services, National \\ Institute of Health, National Institutes of Allergy and \\ Infectious Diseases, Laboratory of Microbial Structure \\ and Function, Rocky Mountain Laboratories, Hamilton, \\ Montana 59840, USA.
}

\section{Summary}

Spontaneous mutants of Neisseria gonorrheae failing to express pili or having diminished levels of piliation were studied with regard to pilin expression. All mutants displayed altered pilin processing detectable as the release of soluble, truncated pilin molecules (S-pilin). Of particular interest was the finding, in one mutant, that substitution of serine for glycine at position -1 of propilin, a highly conserved residue among $\mathrm{N}$-metPhe and related pilins, abolished pilus expression but not S-pilin release. The degree of S-pilin processing and the levels of membrane-associated pilin varied among the different classes of mutants, suggesting that each was blocked at a distinct step of pilus biogenesis. The data support a model in which increased S-pilin processing is a result of a decreased rate of pilus polymerization.

\section{Introduction}

The pili of Neisseria gonorrhoeae are filamentous appendages about $8 \mathrm{~nm}$ in diameter that belong to the family of fimbriae found on Neisseria meningitidis (Potts and Saunders, 1988; Hermodson et al., 1978), Pseudomonas aeruginosa (Pasloske et al., 1985; Frost et al., 1978; Johnson et al., 1986), Moraxella bovis (Marrs et al., 1985), Moraxella nonliquefaciens (Froholm and Sletten, 1977), and Bacteroides nodosus (Elleman and Hoyne, 1984). The

Received 4 August, 1990. "For correspondence. Tel. (313) 936 0847; Fax (313) 7643562 major subunits of all of these organelles, termed pilin, have short (6-7 amino acid) signal sequences, highly conserved hydrophobic amino-terminal domains, and methylated phenylalanine as their mature amino-terminal residues.

Of the many bacterial surface constitutents and extracellular products that are thought to influence the pathogenesis of gonococcal disease, pili are one component that can be unambiguously correlated with virulence. All primary clinical isolates are piliated (Swanson et al., 1987b; Kellog et al., 1968) and non-piliated mutants are avirulent in male volunteers challenged intraurethrally (Kellog et al., 1968; Swanson and Koomey, 1989). Indirect evidence of the import of this colonization factor in the gonococcal-human host relationship can be found in their capacity to undergo antigenic variation such that a single strain can give rise to a broad spectrum of pilus variants at an apparently high rate $\left(10^{-4}\right.$ per cell per generation) (Swanson et al., 1987b, 1985; Koomey et al., 1987; Virji et al., 1983).

Certain aspects of colonial morphology (size, shape, and edge) are reliable and sensitive indicators of gonococcal piliation status and these characteristics have been used extensively to isolate variants and mutants altered in pilus expression. In wild-type strains, these changes in colonial piliation phenotype occur coincidentally with either the expression of antigenically distinct pilin (Swanson and Barrera, 1983) or the failure to express pilin capable of being assembled (Swanson et al., 1985; Bergstrom et al., 1986; Haas et al., 1987). Both of these outcomes can be correlated with changes within the gene encoding pilin, the major subunit of pili, that arise as a result of homologous recombination between multiple partial pilin gene copies (silent loci) and a complete pilin (expression locus) (Swanson et al., 1986; Swanson 1987b; Koomey et al., 1987; Haas and Meyer, 1986). Two other genes, pilA and pilB, have been identified whose gene products influence pilin gene transcription and colonial piliation phenotype (Taha et al., 1988).

Haas and coworkers have described a phase of pilin expression coupled with pilin gene conversion in certain gonococcal pilus ${ }^{+}$variants displaying a non-autoagglutinating piliation (T4) phenotype in which soluble pilin molecules (S-pilin) lacking the first 39 residues present in processed pilin were released or secreted (Haas et al., 1987). They also noted that the amount of S-pilin elaborated appeared to be inversely proportional to the degree of piliation. Other work has shown that pilin molecules 
analogous to S-pilin were made by pilus $^{-}$mutants expressing pilin (Swanson et al., 1986; Koomey et al., $1987)$ and in some pilus ${ }^{+}$variants recovered from infected male volunteers (Swanson et al., 1987b). Little is known about the structure-function relationships of gonococcal pili and pilin, the processes of pilus biogenesis and the nature of the strong correlation between piliation and certain phenotypes. Principally, this situation results from the relative intransigence of gonococci to genetic manipulation, the failure to express gonococcal pilin as pili in a heterologous host such as Escherichia coli or Pseudomonas aeruginosa and the genetic instability of pilin expression in wild-type gonococci. This later obstacle has been alleviated by the ability to construct strains that bear null alleles of the recA gene (Koomey and Falkow, 1987). In order to begin to address these concerns, mutants altered in pilus expression have been isolated from recombination-deficient strains and characterized with regard to piliation status, pilin localization/processing and antigenicity.

\section{Results}

\section{Isolation and characterization of pilus mutants}

The presence of a functioning homologous recombination system mediated, in part, by the gene product of the recA locus has been shown to be required for the antigenic variation and high-frequency 'phase' mutation of gonococcal pilin. Thus strains that bear null alleles of the recA gene are stabilized with regard to pilin expression and in one such strain, VD302, it has been shown that a single class of spontaneous frameshift mutations within the pilin structure gene accounted for on/off pilus expression. In further studies of variants displaying altered colonial piliation phenotypes derived from VD302 $\mathrm{P}^{++}$, two other classes of pilus mutants have been isolated and characterized.

One class of mutants consisted of many independently derived variants displaying the same colonial morphology and phenotypes. They failed to autoagglutinate in liquid culture and showed a unique colonial morphology that might at first sight be viewed as a pilus ${ }^{-}$form. However, by using freshly poured (damp) plates they could be differentiated from isogenic pilus ${ }^{-}$mutants by a slight degree of 'edge' character (Fig. 1). Electron microscopy of these variants revealed that they were piliated, albeit to a lesser degree than the pilus ${ }^{+}$parent, and that the pili were morphologically distinct from those found on their progenitor. By scanning electron microscopy (SEM) the pili were seen to form the large rope-like bundles present on the pilus ${ }^{+}$, autoagglutinating strain. By transmission electron microscopy (TEM), the pilus filaments appeared to have less tendency to laterally aggregate, a more disordered appearance and a wider diameter than that found on VD302 $\mathrm{P}^{++}$pili (Fig. 2). These represented the most frequently arising class of colonial piliation phenotype variants and gave rise to revertants of the $\mathrm{P}^{++}$parental phenotype at approximately the same rate at which they originally arose, i.e. approximately $10^{-6}$ per cell per generation. Based on their shared properties, these variants were presumed to represent the repeated occurrence of the same mutation. More-extensive analysis focused on two isolates, designated CV1 and CV2. Primer extension sequencing of the pilin mRNAs of these two revealed no nucleotide changes and Northern blotting showed no gross alterations in pilin transcript size or abundance (data not shown). This class of mutants did not, therefore, result from pilin gene mutation.

Only a single isolate of another class of mutant was recovered and it failed to express pili as determined by both SEM (Fig. 1) and TEM but unlike pilus ${ }^{-}$mutants previously documented using strain VD302, it produced normal levels of immunoblot-detectable pilin. It could also be distinguished from those previous derivatives by its diminished colony size and increased generation time when propagated on solid media. Sequencing of its pilin mRNA revealed a single nucleotide alteration that changed the codon for amino acid residue -1 or propilin from specifying a glycine to a serine (GGC to AGC, Fig. 3) and this mutant was designated $\mathrm{P}^{-}\left(\mathrm{G}_{-1} \rightarrow \mathrm{S}_{-1}\right)$. The single base change found in the mRNA predicted the presence of a novel HindIII site within the pilin gene and the presence of that mutation within the genome was confirmed by Southern blotting of Hindlll-digested genomic DNA and subsequently by similar restriction endonuclease digestion of the pilE1 locus cloned in E. coli (data not shown). No revertants expressing pili or the parental colonial morphology were recovered using the selective conditions of static broth cultures (selection for pellicle formation).

Pilus/pilin expression in VD302 $P^{++}, C V 1$ and $P^{-}\left(G_{-1} \rightarrow\right.$ $\left.S_{-1}\right)$

Results obtained from immunoblotting of whole-cell lysates of VD302 $\mathrm{P}^{++}, \mathrm{CV} 1$ and $\mathrm{P}^{-}\left(\mathrm{G}_{-1} \rightarrow \mathrm{S}_{-1}\right)$ harvested from plates showed that the pilins expressed by the mutants were altered in mobility relative to that found in the pilus ${ }^{+}$parent (Fig. 4). Pilin from VD302 $\mathrm{P}^{++}$appeared as two species of $M_{r} 18.8 \mathrm{kDa}$ and $19.5 \mathrm{kDa}$, with the lower $M_{r}$ form co-migrating with the major species found in purified pili from that strain. CV1 lysates contained a major species co-migrating with the $M_{r} 19.5 \mathrm{kDa}$ form found for VD302 $\mathrm{P}^{++}$while the major species of pilin expressed by $\mathrm{P}^{-}\left(\mathrm{G}_{-1}\right.$ $>S_{-1}$ ) migrated with an $M_{r}$ of $21 \mathrm{kDa}$. Additionally, minor species of pilin antigen migrating as a doublet of $M_{r}$ $16.5 \mathrm{kDa}$ were detected in lysates of both pili mutants. 
A

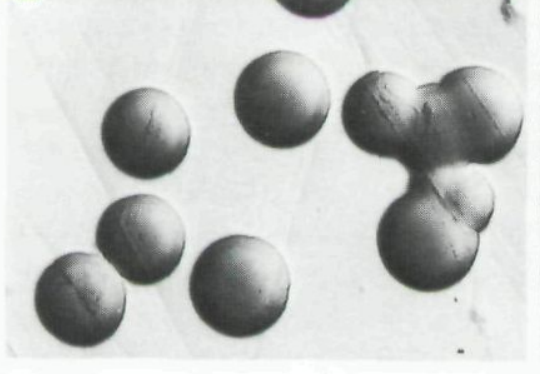

B

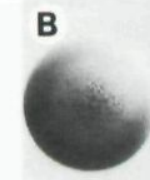

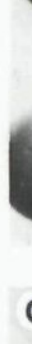

C

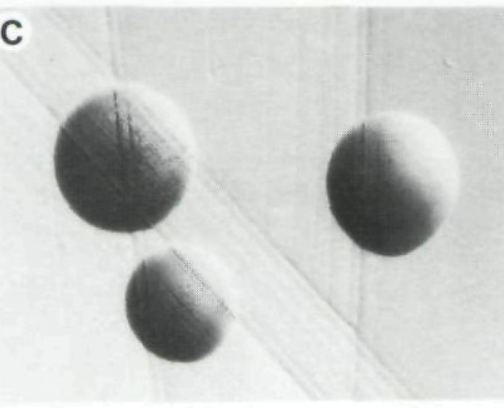

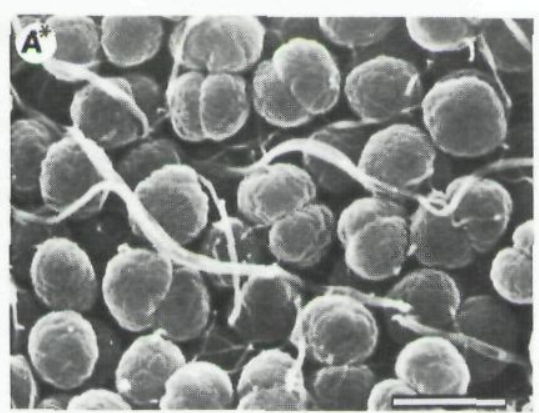
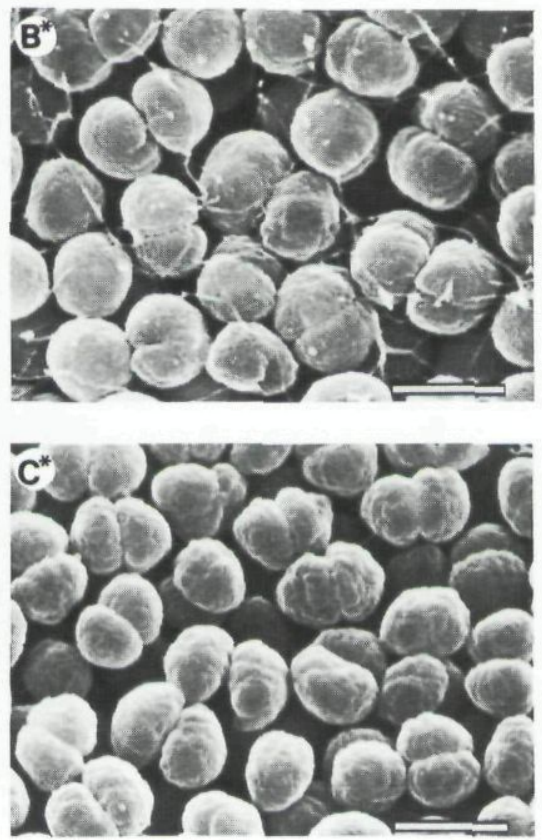

Fig. 1. Colonial morphologies and microscopic appearances $\left({ }^{*}\right.$ SEM) of (A) VD302 $\mathrm{P}^{++}$, (B) CV1, and $(C) P^{-}\left(G_{-1} \rightarrow S_{-1}\right)$.
Immunoblotting of HB101 expressing the cloned pilin genes showed that in all these cases, the relative mobility of pilin expressed in $E$. coli was different from that observed in gonococcal lysates (Fig. 4). The cloned genes of VD302 $\mathrm{P}^{++}$and $\mathrm{CV} 1$ expressed identical doublet patterns of pilin migrating at $M_{\mathrm{r}} 18.5 \mathrm{kDa}$ and $18 \mathrm{kDa}$ while the mutant pilin of $\mathrm{P}^{-}\left(\mathrm{G}_{-1} \rightarrow \mathrm{S}_{-1}\right)$ was detected as a single species of $M_{\mathrm{r}} 18.5 \mathrm{kDa}$.

Pili were purified from $\mathrm{CV} 1$ to determine the relationships between the pilin species detected in whole-cell lysates and assembled pili. The yields of CV1 pili were $2-4 \%$ of that found for VD302 $\mathrm{P}^{++}$cultures. Immunoblotting showed that the major pilin species of $\mathrm{P}^{++}$and $\mathrm{CV} 1$ purified pili had an identical relative mobility of $18.8 \mathrm{kDa}$ but that the CV1 pili lacked a minor pilin species of $M_{r}$ $21.5 \mathrm{kDa}$ present in $\mathrm{P}^{++}$pili (Fig. 5). Also, CV1 pili did not contain the $M_{r} 16.5 \mathrm{kDa}$ species detected in the whole-cell lysate. Amino-terminal sequence analysis of the purified pili confirmed in both preparations that pilin was properly cleaved and methylated at the $\mathrm{N}$-terminal phenylalanine.

\section{Distribution and localization of pilin antigen in pili mutants}

Pilin species analogous to the $M_{\mathrm{r}} 16.5 \mathrm{kDa}$ forms have been detected in MS11 pilus ${ }^{-}$mutants expressing missense pilins (Swanson et al., 1986), MS11 variants expressing reduced levels of piliation (Haas et al., 1987), and some pilus ${ }^{+}$variants recovered from males infected with that same strain (Swanson et al., 1987b). While those pili mutants/variants were generated by pilin gene recombination, this was not the case for the mutants CV1 and $\mathrm{P}^{-}\left(\mathrm{G}_{-1} \rightarrow \mathrm{S}_{-1}\right)$. Protein samples of whole-cell lysates, total membranes and concentrated supernatants were prepared from fluid cultures of the latter strains as well as from VD302 $\mathrm{P}^{++}$, VD302 $\mathrm{P}^{-}$no. 1 (frameshift amino acids 68-70), VD301 $\mathrm{P}^{-}$no. 31 (missense) and VD301 $\mathrm{P}^{-}$ (nonsense amino acid 119) (Koomey et al., 1987). These fractions were analysed by immunoblotting using a monoclonal antibody reactive with pilin (Fig. 6). In contrast to the results using plate-derived organisms, whole-cell lysates of VD302 $\mathrm{P}^{++}$showed only a single species of $M_{r} 18.8 \mathrm{kDa}$. 

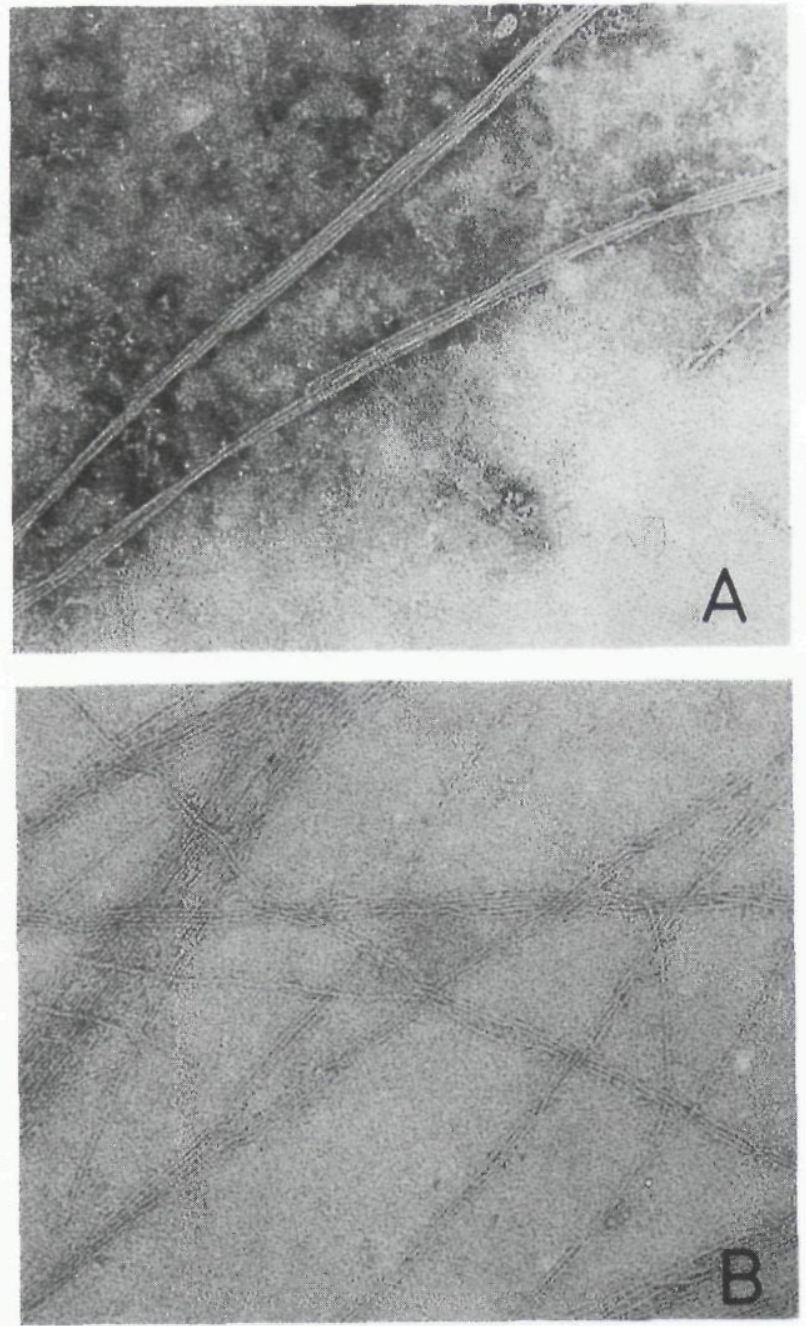

Fig. 2. Pili of VD302 $\mathrm{P}^{++}$and CV1 observed by TEM (90000 $\left.\times\right)$.

Total membranes from this strain contained a small amount of this same-size pilin present in whole cells, while no pilin was detected in culture supernatants. Pilin was not detected in the fractions of VD302 $\mathrm{P}^{-}$no. 1 . Whole cells of $\mathrm{CV} 1$ and $\mathrm{P}^{-}\left(\mathrm{G}_{-1} \rightarrow \mathrm{S}_{-1}\right)$ displayed $M_{\mathrm{r}} 19.5 \mathrm{kDa}$ and $21 \mathrm{kDa}$ pilin species, respectively, along with an $M_{r} 16.5 \mathrm{kDa}$

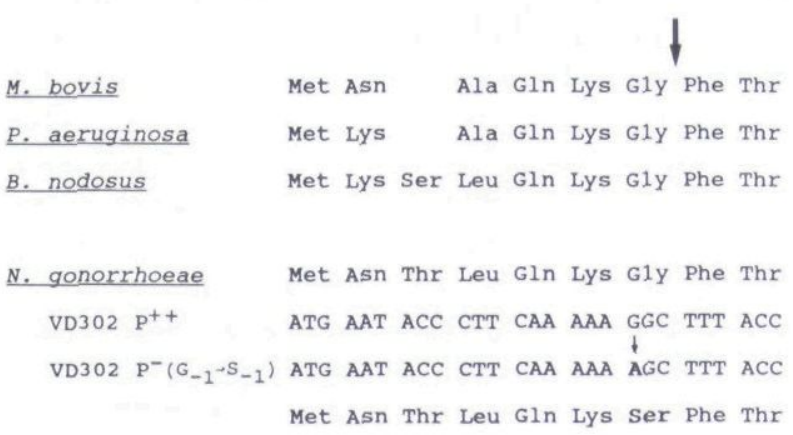

Fig. 3. Comparison of the $\mathrm{N}$-terminal sequences of $\mathrm{N}$-metPhe propilins and mutant pilin expressed by $P^{-}\left(G_{-1} \rightarrow S_{-1}\right)$. species. Total membrane preparations of these strain revealed the distinct presence of the slower migrating forms present in whole cells and that the amounts of membrane-associated pilin found were higher in $\mathrm{P}^{-}\left(\mathrm{G}_{-1}\right.$ $\rightarrow \mathrm{S}_{-1}$ ) than $\mathrm{CV} 1$ which in turn were greater than that seen in VD302 $\mathrm{P}^{++}$. Pilin was not detected in either whole cells or membranes of VD301 $\mathrm{P}^{-}$no. 3. Whole cells of VD301 $\mathrm{P}^{-}$ no. 1 contained $M_{r} 16.5 \mathrm{kDa}$ pilin and no pilin was detected in membranes of this strain. Preliminary results suggest that the $M_{\mathrm{r}} 16.5 \mathrm{kDa}$ pilin species associated with whole cells were periplasmically located but these experiments were complicated by the significant degree of lysis occurring during spheroplast formation.

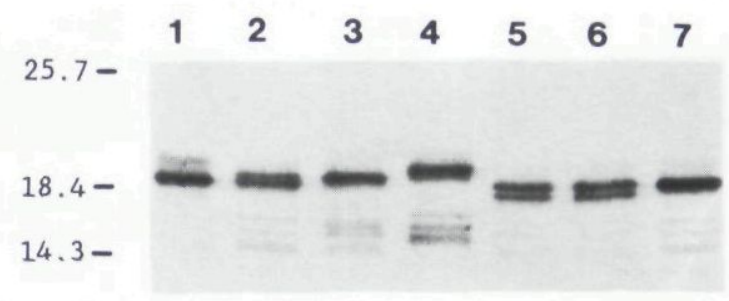

Fig. 4. Immunoblotting of pilin antigen in whole-cell lysates of (2) VD302 $\mathrm{P}^{++}$, (3) CV1, (4) $\mathrm{P}^{-}\left(\mathrm{G}_{-1} \rightarrow \mathrm{S}_{-1}\right)$ harvested from plate cultures, and $E$. coli HB101 expressing the cloned genes of (5) VD302 $\mathrm{P}^{++},(6) \mathrm{CV} 1$, and (7) $\mathrm{P}^{-}\left(\mathrm{G}_{-1} \rightarrow \mathrm{S}_{-1}\right)$. Lane 1 was loaded with $100 \mathrm{ng}$ of purified VD302 $\mathrm{P}^{++}$ pili. The blot was developed using monoclonal antibody $\mathrm{O} 2$ at a dilution of $1: 1000$.

Significant amounts of $M_{\mathrm{r}} 16.5 \mathrm{kDa}$ pilin were specifically released into the culture supernatant of $\mathrm{CV}_{1}, \mathrm{P}^{-}$ $\left(G_{-1} \rightarrow S_{-1}\right)$ and VD301 $P^{-}$no. 1 while the supernatant of VD301 $\mathrm{P}^{-}$no. 3 contained an $M_{\mathrm{r}} 8 \mathrm{kDa}$ pilin species. The levels of pilin detected in these supernatants ranged from $0.2-1.2 \mathrm{mg} \mathrm{I}^{-1}$ in concentration. The $M_{\mathrm{r}} 16.5 \mathrm{kDa}$ pilin was purified from culture supernatants of $\mathrm{P}^{-}\left(\mathrm{G}_{-1} \rightarrow \mathrm{S}_{-1}\right)$ and amino-terminal sequence analysis showed that the first seven residues matched amino acids 40 to 46 of mature pilin. These results were identical to that found for the $M_{r}$ $16 \mathrm{kDa}$ S-pilin found in a pilus ${ }^{+}$variant (Haas et al., 1987). The data obtained from liquid cultures of VD301 $\mathrm{P}^{-}$no. 1 and VD301 $\mathrm{P}^{-}$no. 3 were different from that found using plate-derived cells (Koomey et al., 1987). To address this discrepancy, analysis of plate-derived whole-cell lysates of those two mutants was repeated and the results (Fig. 7) revealed that VD301 $\mathrm{P}^{-}$no. 3 cells contained an $M_{\mathrm{r}} 15 \mathrm{kDa}$ and $8 \mathrm{kDa}$ species while VD301 $\mathrm{P}^{-}$no. 1 cells contained equivalent amounts of $M_{\mathrm{r}} 18.5 \mathrm{kDa}$ and $16.5 \mathrm{kDa}$ forms. As found with the other pilin genes cloned in $E$. coli, there was no evidence of a truncated or faster-migrating form of pilin analogous to that seen in gonococci. 


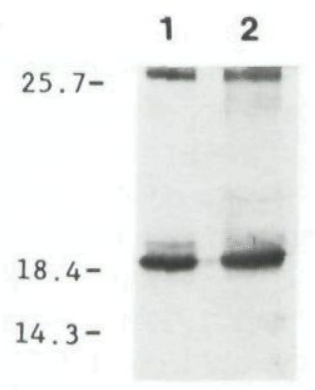

Fig. 5. Immunoblotting of purified pili derived from (1) VD302 $\mathrm{P}^{++}$and (2) $\mathrm{CV} 1$. The blot was developed using monoclonal antibody $\mathrm{O} 2$ at a dilution of $1: 1000$.

Studies of antigenic cross-reactivity between $\mathrm{P}$. aeruginosa PAK and gonococcal pili

Watts and coworkers demonstrated that polyclonal rabbit antisera raised against PAK pili of $P$. aeruginosa would cross-react in an immunoblot with purified MS11 pili (Watts et al., 1983a). They reasoned that since the only region of homology between PAK and gonococcal pilins is found at the amino terminus (residues 1-22), it was likely that epitopes within this common region were responsible for the observations. This possibility was tested by asking whether PAK pili antisera would react with the $M_{\mathrm{r}} 16.5 \mathrm{kDa}$ $\mathrm{S}$-pilin that lacked those amino-terminal residues. PAK

\section{$\begin{array}{llllll}1 & 2 & 3 & 4 & 5 & 6\end{array}$}
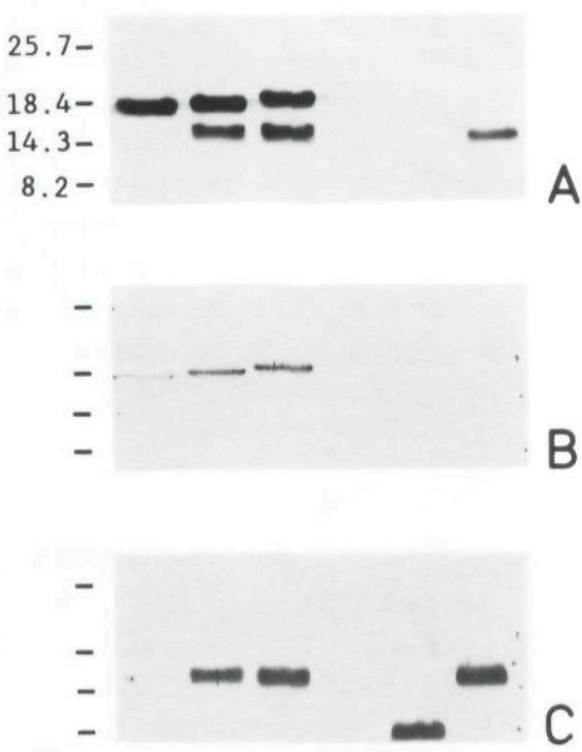

Fig. 6. Immunoblotting of whole-cell lysates (A), total membranes (B), and concentrated culture supernatants (C) of (1) VD302 $\mathrm{P}^{++}$, (2) CV1, (3) $P^{-}\left(G_{-1} \rightarrow S_{-1}\right)$, (4) VD302 $P^{-}$no. 1, (5) VD301 $P^{-}$no. 3, and (6) VD301 $\mathrm{P}^{-}$no. 1. Samples were standardized according to total colony-forming units $\left(5 \times 10^{6}\right)$ (for A), total protein (for B), and volume of supernatant (for C). The blot was developed using monoclonal antibody $\mathrm{O} 2$ at a dilution of $1: 1000$. antisera reacted with the $M_{\mathrm{r}} 18.5 \mathrm{kDa}$ pilin of VD302 $\mathrm{P}^{++}$ and the $M_{r} 19.5 \mathrm{kDa}$ pilin of CV1 but failed to react with the faster-migrating species in whole cells of $\mathrm{CV} 1$ and $\mathrm{P}^{-}\left(\mathrm{G}_{-1}\right.$ $\left.\rightarrow S_{-1}\right)$ (Fig. 8). Surprisingly, this serum did not react with the $M_{\mathrm{r}} 21 \mathrm{kDa}$ pilin present in $\mathrm{P}^{-}\left(\mathrm{G}_{-1} \rightarrow \mathrm{S}_{-1}\right)$. The PAK-specific antibodies also failed to detect the S-pilin in supernatants (data not shown).

\section{Evidence for gonococcal pilin processing in E. coli}

On the basis of the specific reactivity pattern seen with the PAK antisera, we inferred that it might be a useful reagent for addressing the status of gonococcal pilin expressed in $E$. coli. Duplicate immunoblots of whole-cell lysates of $E$. coli expressing the cloned pilin genes of strains VD302 $\mathrm{P}^{++}, \mathrm{CV} 1$ and $\mathrm{P}^{-}\left(\mathrm{G}_{-1} \rightarrow \mathrm{S}_{-1}\right)$ were probed with PAK

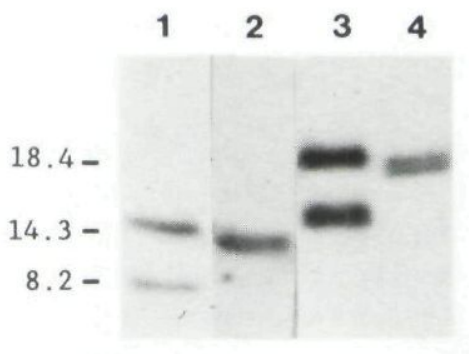

Fig. 7. Immunoblotting of whole-cell lysates of (1) VD301 $\mathrm{P}^{-}$no. 3 and (3) VS301 $\mathrm{P}^{-}$no. 1 harvested from plates, and $\mathrm{HB} 101$ expressing the pilin genes from (2) VD301 $\mathrm{P}^{-}$no. 3 and (4) VD301 $\mathrm{P}^{-}$no. 1. The blot was developed using monoclonal antibody at a dilution of 1:1000.

antisera and VD302 $\mathrm{P}^{++}$pili antisera (Fig. 9). As an internal control, each blot also contained whole-cell lysate of VD302 $\mathrm{P}^{++}$cells grown on plates, and, under the conditions employed, the two antisera reacted to a similar degree with the pilin in this sample. In contrast to the VD302 pilin antisera that reacted equally well with the various pilins expressed in E. coli, the PAK antibodies reacted only with the $M_{r} 18 \mathrm{kDa}$ form found in clones of the VD302 $\mathrm{P}^{++}$and CV1 pilin genes and the signal detected was weak.

\section{Discussion}

The non-piliated state of $\mathrm{P}^{-}\left(\mathrm{G}_{-1} \rightarrow \mathrm{S}_{-1}\right)$ clearly indicates a critical role for the amino acid at position -1 of pilin in the assembly of gonococcal pili. This idea is supported by the extreme degree of conservation of this residue in other $\mathrm{N}$-metPhe pilins, the closely related tcpA gene product of Vibrio cholerae (Faast et al., 1989), and the pilin-like comG open reading frames 3,4 , and 5 of Bacillus subtilis (Albano et al., 1989). On the basis of the retarded migration of the mutant polypeptide, it appears that this pilin is incapable 


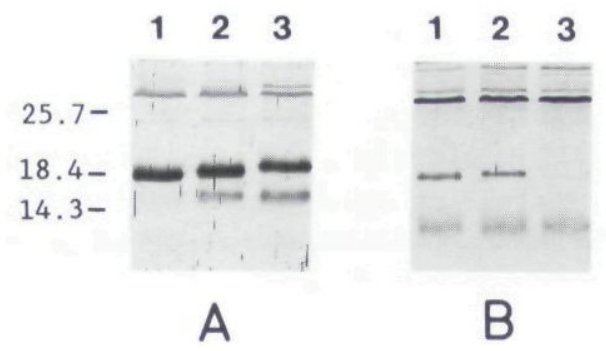

Fig. 8. Immunoblotting of whole-cell lysates of (1) VD302 $\mathrm{P}^{++}$, (2) CV1, (3) $\mathrm{P}^{-}\left(\mathrm{G}_{-1} \rightarrow \mathrm{S}_{-1}\right)$ from liquid cultures using rabbit antisera raised against VD302 $\mathrm{P}^{++}$pili (Panel A, 1:1000 dilution) and PAK pilus antisera (Panel B, 1:500 dilution).

of being proteolytically processed at its amino terminus and that this accounts for the non-piliated phenotype. This conclusion is further supported by the failure of the mutant pilin to react with PAK antisera in immunoblotting since it is extremely difficult to envisage how an amino acid substitution in a part of the molecule not present in processed pilin could abolish the antigenicity of that polypeptide.

Because of the nature of processing that takes place during pilus biogenesis, the highly conserved aminoterminal domain of propilin must function both as a signal sequence (Strom and Lory, 1987) and in pilus assembly (Watts et al., 1983b). The presence of $\left(G_{-1} \rightarrow S_{-1}\right)$ pilin in total membranes along with the elaboration of S-pilin derived from mutant pilin implies that the polypeptide is defective for assembly and not membrane translocation. Studies of localization of PAK pilin mutants in P. aueruginosa have also shown that proteolytic processing at the Gly-Phe junction does not appear to be required for pilin to reach the bacterial surface (Pasloske and Paranchych, 1988b).

The class of mutants exemplified by CV1 yielded greatly reduced amounts of purified pili and the pili that were present appeared aberrant by both electron microscopic techniques. Using sodium dodecyl sulphate/polyacrylamide gel electrophoresis (SDS-PAGE) and immunoblotting, CV1 purified pili lacked a minor slower-migrating pilin species found in VD302 $\mathrm{P}^{++}$pili and the major form seen in the purified pili did not co-migrate with pilin found in whole cells or membranes. CV1 pilin in whole cells migrated slower than that seen in VD302 $\mathrm{P}^{++}$whole cells but a similar form could be detected in VD302 $\mathrm{P}^{++}$whole cells grown on plates. It appears that some post-translational modification of pilin required for efficient assembly is diminished or missing in these mutants. Attempts to begin to identify the genetic lesion(s) responsible for this phenotype by genetic complementation have been complicated by the relatively high rate of spontaneous reversion.

Both of the mutants isolated here have increased levels of membrane-associated pilin compared with VD302 $\mathrm{P}^{++}$ and their presence in $\mathrm{P}^{-}\left(\mathrm{G}_{-1} \rightarrow \mathrm{S}_{-1}\right)$ argues against the possibility that the pilin detected represented contamination with assembled pili. By analogy with filamentous phage assembly (Smilowitz et al., 1972) as well as PAK and F-pilus assembly (Watts et al., 1982; Moore et al., 1981), the enriched pools of pilin in these assembly mutants provided evidence that membrane-bound pilin represents an intermediate step in pilus assembly. The failure to find membrane pilin pools in VD301 $\mathrm{P}^{-}$no. 1 and VD301 $\mathrm{P}^{-}$no. 3 that have mutations altering the carboxyterminal domains of pilin suggest that they are deficient in a different, and presumably subsequent, step of pilus assembly.

The reactivity of PAK pili antisera with gonococcal pilin found in these studies confirms the findings of Watts et al. The failure of S-pilin and $\left(G_{-1} \rightarrow S_{-1}\right)$ pilin to react shows that the cross-reactive epitope(s) are localized to the amino terminus and that proper proteolytic processing is necessary to create or expose the epitope(s). The ability of the sera to detect the slower-migrating pilin in CV1 implies that this pilin is proteolytically clipped and that its altered mobility from $\mathrm{P}^{++}$pilin is due to differences in some other form of post-translational modification. When gonococcal pilin expressed in E. coli was examined, the PAK antisera reacted only with the faster-moving species of the two forms seen with $\mathrm{P}^{++}$and $\mathrm{CV} 1$ pilin and since $\left(\mathrm{G}_{-1} \rightarrow \mathrm{S}_{-1}\right)$ pilin failed to display this faster species, no reactivity was found for that sample. Therefore, the $G_{-1} \rightarrow S_{-1}$ mutation inhibited processing of pilin in $E$. coli just as it did in gonococci, suggesting that $E$. coli may possess a protease related to that operating in gonococci. Similar findings have been made for wild-type and mutant PAK pilins expressed in E. coli (Pasloske and Paranchych, 1988a).

The precise signals that trigger the alternate processing of pilin and expression of S-pilin are not known. On the basis of previous work and the results presented here, it is clear that S-pilin production occurs coincidentally with reduced levels of piliation or the absence of pilus

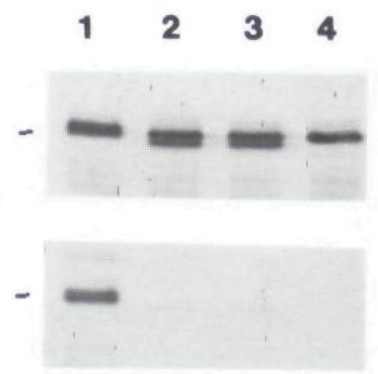

Fig. 9. Immunoblotting of whole-cell lysates of (1) VD302 $\mathrm{P}^{++}$(from plates), and HB101 expressing the pilin genes from (2) VD302 $\mathrm{P}^{++}$, (3) CV1, (4) $\mathrm{P}^{-}\left(\mathrm{G}_{-1} \rightarrow \mathrm{S}_{-1}\right)$ using rabbit antisera raised against VD302 $\mathrm{P}^{++}$ pili (top Panel) and PAK pilus antisera (bottom Panel). 
assembly. The elaboration of S-pilin by such a diverse group of mutants favours the notion that it is the result rather than the cause of non-assembly or reduced piliation. In such a scheme, it would seem that the signal that activates S-pilin processing is a reduced rate of pilin polymerizaton. Assuming that the protease responsible is present at all times, pilin being actively assembled remains in a protease-susceptible state for only a short time. A decrease in the rate of polymerization resulting from intrinsic structural features of variant and mutant pilins or from the occurrence of mutations in other genes involved in assembly thus increases the time in which pilin remains in a susceptible state. Differences in the degree of processing then would result from variability in the rate of polymerization and, in the case of non-piliated pilin mutants, the degree of accessibility or susceptibility of that particular pilin to the peptidase. The results also indicate that S-pilin can be significantly modified by the conditions of cultivation, with the process being most efficient in liquid cultures.

Many roles can be envisaged for S-pilin processing in pathogenesis (such as in adsorbing pilus-specific antibodies at a distance from the cell surface) or in the modulation of pilus extrusion and retraction. Alternatively, it may be that this is a mechanism by which cells alleviate the detrimental effects of pilin retained in the membrane under conditions where it is not being efficiently translocated and polymerized since the pilin gene is constitutively transcribed (Swanson et al., 1985). This situation might be analogous to that occurring in E. coli expressing high levels of hybrid proteins that accumulate in the membrane (Ito et al., 1981). Evidence for such a role for S-pilin processing is found in the genetic instability and small colony phenotype of $\mathrm{P}^{-}\left(\mathrm{G}_{-1} \rightarrow \mathrm{S}_{-1}\right)$ grown on plates. This mutant throws off large colony derivatives with shorter generation times and these variants have mutations in pilE1 that preclude synthesis of full-size pilin (our unpublished data), suggesting that poor growth on plates is due to pilin expression in the absence of assembly. When grown in liquid cultures under conditions in which S-pilin processing is more efficient, the generation time is equivalent to that of the other pilus ${ }^{-}$mutants. Although the significance of this form of pilin processing remains obscure, alterations in the levels of S-pilin production appears to be a sensitive marker for concurrent changes in gonococcal pilus expression and assembly.

\section{Experimental procedures}

\section{Bacterial strains and cultivation conditions}

N. gonorrhoeae strains VD302 $\mathrm{P}^{++}$, VD302 $\mathrm{P}^{-}$no. $1, V^{2} 302 \mathrm{P}^{-}$no. 1 and VD301 $\mathrm{P}^{-}$no. 3 and conditions of growth on solid media have been described (Koomey et al., 1987). VD302 $\mathrm{P}^{-}$no. 1 expresses truncated pilin resulting from a frameshift mutation in the pilE1 locus within the codons for amino acid residues 68-70, VD301 $\mathrm{P}^{-}$no. 1 expresses a full-size variant pilin incapable of being assembled (analogous to the P-rp+ phenotype (Swanson et al., 1985) or the B1 variant of Haas (Haas et al., 1987)) and VD301 $\mathrm{P}^{-}$no. 3 expresses truncated pilin resulting from a pilin gene nonsense mutation within the codon for aa residue 119 . For detection of S-pilin, strains were grown to mid-log phase in Catlins Defined media (Gibco). Conditions of static broth cultures and selection for pellicle formation have been published (Koomey et al., 1987).

\section{Nucleic acid manipulations}

Methods of chromosomal and plasmid DNA isolation, Southern blotting, and recombinant DNA techniques have been detailed previously (Koomey and Falkow, 1987). The $2.7 \mathrm{~kb}$ EcoRI-Clal fragments encompassing the pilE1 locus were cloned into pBR325 and propagated in E. coli HB101. Sequencing of pilin mRNAs by primer extension/dideoxy chain termination and Northern blotting were performed according to published protocols (Bergstrom et al., 1986; Swanson et al., 1985).

\section{Pilus purification and cell fractionation}

Pili were purified from organisms harvested from plates using a modification of the method described by Brinton et al., (1978) utilizing repeated cycles of solubilzation $(0.15 \mathrm{M}$ ethanolamine$\mathrm{HCl}$ buffer $\mathrm{pH} 10.4$ ) and isoelectric precipitation (dialysis versus $0.05 \mathrm{M}$ Tris- $\mathrm{HCl} \mathrm{pH} 7.5 / 0.15 \mathrm{M} \mathrm{NaCl}$ (Tris-saline)) and all steps were performed at $4^{\circ} \mathrm{C}$. Pilus protein concentrations were measured using the Coomassie Brilliant Blue Method (Spector, 1978) using bovine serum albumin as a standard. Purity of samples was determined by SDS-PAGE and Coomassie staining. Total gonococcal membranes were isolated by spheroplast formation followed by sucrose gradients as described (Johnston and Gotschlich, 1974).

\section{Purification of S-pilin}

Supernatants of broth cultures were cooled to $4^{\circ} \mathrm{C}$ and brought to $10 \%$ trichloroacetic acid. The precipitate was removed by centrifugation at $17000 \times g$ for $10 \mathrm{~min}$ and resuspended in Tris-saline buffer. The suspension was clarified by an additional centrifugation at $48000 \times g$ for $30 \mathrm{~min}$. The clarified supernate was then adjusted to $10 \%$ trifluoroacetic acid (TFA) and the precipitate was collected by centrifugation. The precipitated material was solubilized in $8 \mathrm{M}$ guanidine- $\mathrm{HCl}$ with $0.05 \%$ TFA and loaded onto a Whatman Partisal-10 ODS-2 column. Proteins and peptides were eluted with a $20-85 \%$ gradient of acetonitrile in water containing 0.05 TFA at a flow rate of $1.0 \mathrm{ml} \mathrm{min}^{-1}$. One millilitre samples were collected, concentrated on a Savant Speedvac concentrator centrifuge, and analysed by SDS-PAGE and immunoblotting.

\section{Determination of amino-terminal amino acids}

Purified pili or S-pilin (50nM) was precipitated with 10\% ice-cold TFA and the precipitate washed seqentially with ethanol and 
acetone and air-dried. The precipitate was then dissolved in $50 \%$ $(\mathrm{v} / \mathrm{v})$ acetic acid and $2.5 \mathrm{nM}$ was introduced into a model 470A 477A protein/peptide pulse-liquid sequencer with an online PTH analyser (Applied Biosystems, Inc.).

\section{SDS-PAGE and immunoblotting}

SDS-PAGE was a variation of Laemmli's method (Laemmli, 1970) as described previously (Blake and Gotschlich, 1984). Procedures for immunoblotting (Western blotting) have been described previously (Blake et al., 1984). Whole-cell lysates were prepared from organisms swabbed from plates or liquid cultures and standardized by optical density at $600 \mathrm{~nm}$ and total protein concentration. Proteins in culture supernatants of defined media were concentrated by trichloroacetic acid precipitation followed by ethanol- and acetone washes and resuspension in sample buffer. Rabbit polyclonal antiserum 2-66 was raised by immunization with purifed VD302 $\mathrm{P}^{++}$pili, and rabbit PAK pilus antisera was a gift of Emil Gotschlich. The pilin-specific monoclonal antibody $\mathrm{O} 2$ has been described and reacts with an invariant epitope of gonococcal pilin (Swanson et al., 1987a). Prestained low-range molecular weight protein electrophoresis markers (Diversified Biotech and BRL-Gibco) were used to standardize geis.

\section{Transmission- and scanning electron microscopy}

Transmission electron microscopy (using $0.5 \%$ phosphotungstic acid (PTA) as a negative stain) and scanning electron microscopy of whole colonies were performed as detailed (Swanson et al., $1971 ; 1985)$

\section{Acknowledgements}

We thank Emil Gotschlich for helpful discussions and suggestions during the course of this work. This work was supported by Public Health Service grants Al 19469, Al 10615, and Al 27837 from the National Institutes of Health (USA), funds from The World Health Organization, grant project Dnr 07922 from the Swedish Medical Council (S.B.), and by a fellowship from the Pew Scholars Programme in the Biomedical Sciences to M.K.

\section{References}

Albano, M., Breitling, R., and Dubnau, D.A. (1989) Nucleotide sequence and genetic organization of the Bacillus subtilis comG operon. J Bacteriol 171: 5386-5404.

Bergstrom, S., Robbins, K., Koomey, J.M., and Swanson, J. (1986) Piliation control mechanisms in Neisseria gonorrhoeae. Proc Natl Acad Sci USA 83: 3890-3894.

Blake, M.S., and Gotschlich, E.C. (1984) Purification and partial characterization of the opacity-associated proteins of Neisseria gonorrhoeae. J Exp Med 159: 452-462.

Blake, M.S., Johnston, K.H., Russell-Jones, G.J., and Gotschlich, E.C. (1984) A rapid, sensitive method for detection of alkaline phosphatase-conjugated anti-antibody on Western blots. Anal Biochem 136: 175-179.

Brinton, C.C., Bryan, J., Dillon, D.A. Guerina, N., Jacobson, L.J., Labik, A., Lee, S., Levine, A., Lim, S., McMichael, J., Polen, S., Rogers, K., To, C.C., and To, S.C.-M. (1978) Uses of pili in gonorrhea control: role of bacterial pili in disease, purification and properties of gonococcal pili, and progress in the development of a gonococcal pilus vaccine for gonorrhea. In Immunobiology of Neisseria gonorrhoeae. Brooks, G.F., Gotschlich, E.C., Holmes, K.K., Sawyer, W.D., and Young, F.E. (eds). Washington, D.C.: American Society for Microbiology, pp. 155-178.

Elleman, T.C., and Hoyne, P.A. (1984) Nucleotide sequence of the gene encoding pilin of Bacteroides nodosus, the causal organism of ovine footrot. J Bacteriol 160: 1184-1187.

Faast, R., Ogierman, M.A., Stroeher, U.H., and Manning, P.A. (1989) Nucleotide sequence of the structural gene, $\operatorname{tcp} A$, for a major pilin subunit of Vibrio cholerae. Gene 85: 227-231.

Froholm, L.O., and Sletten, K. (1977) Purification and N-terminal sequence of a fimbrial protein from Moraxella nonliquefaciens. FEBS Lett 73: 29-32.

Frost, L.S., Carpenter, M., and Paranchych, W. (1978) N-methylphenylalanine at the $\mathrm{N}$-terminus of pilin isolated from Pseudomonas aeruginosa K. Nature 271: 87-89.

Haas, R., and Meyer, E.F. (1986) The repertoire of silent pilus genes in Neisseria gonorrhoeae: evidence for gene conversion. Cell 44: 107-115.

Haas, R., Schwarz, H., and Meyer, T.F. (1987) Release of soluble pilin antigen coupled with gene conversion in Neisseria gonorrhoeae. Proc Natl Acad Sci USA 84: 9079-9083.

Hermodson, M.A., Chen, K.C., and Buchanan, T.M. (1978) Neisseria pili protein: amino-terminal amino acid sequences and identification of an unusual amino acid. Biochemistry 17: 442-445.

Ito, K., Bassford, P.J., Jr and Beckwith, J. (1981) Protein localization in E. coli: is there a common step in the secretion of periplasmic and outer-membrane proteins. Cell 24: 707-717.

Johnson, K., Parker, M.L., and Lory, S. (1986) Nucleotide sequence and transcriptional initiation start site of two Pseudomonas aeruginosa pilin genes. J Biol Chem 261: 15703-15708.

Johnston, K.H., and Gotschlich, E.C. (1974) Isolation and characterization of the outer membrane of Neisseria gonorrhoeae. $J$ Bacteriol 119: 250-257.

Kellog, D.S., Cohen, I.R., Norins, L.C., Schroeter, A.L., and Reising, G. (1968) Neisseria gonorrhoeae. II. Colonial variation and pathogenicity during 35 months in vitro. J Bacteriol 96: 596-605.

Koomey, J.M., and Falkow, S. (1987) Cloning of the recA gene of Neisseria gonorrhoeae and construction of gonococcal recA mutants. J Bacteriol 169: 790-795.

Koomey, M., Gotschlich, E.C., Robbins, K., Bergstrom, S., and Swanson, J. (1987) Effects of recA mutations on pilus antigenic variation and phase transitions in Neisseria gonorrhoeae. Genetics 117: 391-398.

Laemmli, U.K. (1970) Cleavage of structural proteins during the assembly of the head of the bacteriophage T4. Nature 227: 680-685.

Marrs, C.F., Schoolnik, G., Koomey, J.M., Hardy, J., Rothbard, J., and Falkow, S. (1985) Cloning and sequencing of a Moraxella bovis pilin gene. J Bacteriol 163: 132-139.

Moore, D., Sowa, B.A., and Ippen-Ihler, K. (1981) Location of an F-pilin pool in the inner membrane. J Bacteriol 146: 251-259.

Pasloske, B.L., and Paranchych, W. (1988a) The expression of Pseudomonas aeruginosa PAK pilin gene mutants in Escherichia coli. Mol Microbiol 2: 185-195.

Pasloske, B.L., and Paranchych, W. (1988b) The expression of mutant pilins in Pseudomonas aeruginosa: fifth positions glutamate affects pilin methylation. Mol Microbiol 2: 489-495.

Pasloske, B.L., Finlay, B.B., and Paranchych, W. (1985) Cloning and sequencing of the Pseudomonas aeruginosa PAK pilin gene. FEBS Lett 183: 408-412. 
Potts, W.J., and Saunder, J.R. (1988) Nucleotide sequence of the strucural gene for class I pilin from Neisseria meningitidis: homologies with the pilE locus of Neisseria gonorrhoeae. Mol Microbiol 2: 647-653.

Smilowitz, H., Carson, J., and Robbins, P.W. (1972) Association of newly synthesized major $\mathrm{f} 1$ coat protein with the infected host cell inner membrane. J Supramol Struct 1: 8-13.

Spector, T. (1978) Refinement of the coomassie blue method of protein quantitation. A simple and linear spectrophotometric assay for less than or equal to 0.5 to 50 microgram of protein. Anal Biochem 86: 142-146.

Strom, M.S., and Lory, S. (1987) Mapping of export signals of Pseudomonas aeruginosa pilin with alkaline phosphatase fusions. J Bacteriol 169: 3181-3188.

Swanson, J., and Barrera, O. (1983) Gonococcal pilus subunit size heterogeneity correlates with transitions in colony piliation phenotype, not with changes in colony opacity. J Exp Med 158: 1459-1472.

Swanson, J., and Koomey, J.M. (1989) Mechanisms for variation of pili and outer membrane protein II in Neisseria gonorrhoeae. In Mobile DNA. Berg, D., and Howe, M. (eds). Washington, D.C.: American Society for Microbiology, pp 743-761.

Swanson, J., Kraus, S.J. and Gotschlich, E.C (1971) Studies to gonococcus infection. I. Pili and zones of adhesion: their relation to gonococcal growth patterns. J Exp Med 134: 886-906.

Swanson, J., Bergstrom, S., Barrera, O., Robbins, K., and Corwin, D. (1985) Pilus gonococcal variants. Evidence for multiple forms of piliation control. J Exp Med 162: 729-744.
Swanson, J., Bergstrom, S., Robbins, K., Barrera, O., Corwin, D., and Koomey, J.M. (1986) Gene conversion involving the pilin structural gene correlates with pilus + in equilibrium with piluschanges in Neisseria gonorrhoeae. Cell 47: 267-276.

Swanson, J., Robbins, K., Barrera, O., and Koomey, J.M. (1987a) Gene conversion variations generate structurally distinct pilin polypeptides in Neisseria gonorrhoeae. J Exp Med 165: 1016-1025.

Swanson, J., Robbins, K., Barrera, O., Corwin, D., Boslego, J., Ciak, J., Blake M., and Koomey, J.M. (1987b) Gonococcal pilin variants in experimental gonorrhoea. J Exp Med 165: 13441357.

Taha, M.K., So, M., Seifert, H.S., Billyard, E., and Marchal, C. (1988) Pilin expression in Neisseria gonorrhoeae is under both positive and negative transcriptional control. EMBO $J$ 7: 4367-4378.

Virji, M., Heckels, J.E., and Watt, P.J. (1983) Monoclonal antibodies to gonococcal pili: studies on antigenic determinants on pili from variants of strain P9. J Gen Microbiol 129: 1965-1973.

Watts, T.H., Worobec, E.A., and Paranchych, W. (1982) Identification of pilin pools in the membranes of Pseudomonas aeruginosa. J Bacteriol 152: 687-691.

Watts, T.H., Sastry, P.A., Hodges, R.S. and Paranchych, W. (1983a) Mapping of the antigenic determinants of Pseudomonas aeruginosa PAK polar pili. Infect Immun 42: 113-121.

Watts, T.H., Kay, C.M., and Paranchych, W. (1983b) Spectral properties of three quaternary arrangements of Pseudomonas pilin. Biochemistry 22: 3640-3646. 
This document is a scanned copy of a printed document. No warranty is given about the accuracy of the copy. Users should refer to the original published version of the material. 